\title{
Rainfall reliability, drought and flood vulnerability in Botswana
}

\author{
Rejoice Tsheko \\ University of Botswana, Faculty of Agriculture, Department of Agricultural Engineering and Land Planning, Private Bag 0027, \\ Gaborone, Botswana
}

\begin{abstract}
Rainfall data from 14 stations (cities, towns and major villages) spanning 26 years (1970 to 1995) were used to calculate reliability and vulnerability of rainfall in Botswana. Time series data for 72 years were generated from the long-term rainfall gauging stations and the number of wet and dry years determined. Apart from Mahalapye, most places have rainfall reliability greater than 0.5 but less than 0.7. Palapye and Serowe are the most vulnerable to flooding. During the 1995 floods, $87 \%$ of casualties were from these areas. Other factors such as rivers, topography, land use etc. can influence flooding vulnerability, but these have not been dealt with in the study, and hence vulnerability is purely based on rainfall amounts. Using two methods, the correlation coefficient is $0.9(\mathrm{p}<0.005)$ for reliability and risk values. The first method was originally developed for water resource system performance evaluation and the second method is based on dry/wet year sequences.
\end{abstract}

Keywords: rainfall, reliability, risk, flood, drought, vulnerability, Botswana.

\section{Introduction}

It is well known that rainfall in Botswana is generally low, erratic and unreliable. To define how severe and how frequent periods of droughts and floods are, it is useful to quantify the above statement. Hashimoto et al., 1982 proposed criteria that capture particular aspects of possible water resource system (WRS) performance. These criteria are very important during drought, peak demands, or extreme weather sequences. The two criteria for evaluating the performance of a WRS are reliability, which measures how likely a system is to fail, and vulnerability, which measures the severity of the consequences of failure (Hashimoto et al., 1982). Failure frequency and system reliability are indices, which are normally used to describe the system's performance (Hall and Dracup, 1970). It has been customary to refer to the safe yield of a reservoir as if it were a guaranteed minimum yield. Analysis of the historical record or simulated stream flow provides no evidence regarding the reliability of a reservoir (Linsly et al., 1982). When a stochastic analysis is accepted as a realistic example of what may happen in the future, storage probability curves can provide useful information (Linsly et al., 1982).

A system's output state or status can be denoted by a random variable $X_{t}$ at time $t$, where $t$ is discrete. The possible values of $X_{t}$ can be partitioned into two sets: $\mathrm{S}$, the set of all satisfactory outputs, and F, the set of all failure outputs. At any time $t$ the system output can be in any of the two sets, hence the reliability of a system can be described by frequency or probability $\boldsymbol{\alpha}$ that a system is in a satisfactory state (i.e. rainfall of year $\mathbf{n}$ is above long-term mean rainfall) (Loucks et al., 1981; Hashimoto et al., 1982).

$$
\alpha=\operatorname{Prob}\left[X_{t} \in S\right]
$$

The risk, $\mathbf{r}$ or probability of failure is one minus the reliability.

\footnotetext{
푱 +267 3650128; fax: +267 328753; e-mail: rtsheko@bca.bw
} Received 7 February 2003; accepted in revised form 23 July 2003.
System vulnerability refers to the likely magnitude of failure, if failure occurs. It should be noted that even if the probability of failure is small, attention should be paid to consequences of failure.

To construct a mathematical index of system vulnerability $\mathbf{v}$, assume that the system performance variable $X_{t}$ can take discrete values $\mathrm{x}_{1}, \ldots, \mathrm{x}_{\mathrm{n}}$ To construct a quantitative indicator of system vulnerability to severe failure, assign to each failure state $x_{j} \in F$ a numerical indicator of the severity of the state (i.e. cost function, denoted by $s_{\mathrm{j}}$. Let $\mathrm{e}_{\mathrm{j}}$ be the probability that $\mathrm{x}_{\mathrm{j}}$, corresponding to $\mathrm{s}_{\mathrm{j}}$, is the most unsatisfactory and severe outcome, hence vulnerability (Loucks et al. 1981; Hashimoto et al. 1982) is estimated as:

Windsor (1973) developed and provided a solution for non-linear cost function curves for the damage centres; these types of functions will be needed if Eq. (3) is to be used to calculate vulnerability. Equation (4) does not require estimation of a cost function although it gives the most unsatisfactory and severe outcome, hence vulnerability. This equation is used to calculate vulnerability in this work.

$$
v=\operatorname{Max}\left[X_{t}-X_{o}\right]
$$

where $\mathrm{X}$ is some threshold value i.e. the mean long-term minimum or maximum rainfall. For drought vulnerability, $\mathrm{X}$ is the mean long-term minimum rainfall, while for flood vulnerability $\mathrm{X}_{\mathrm{o}}$ is the mean long-term maximum rainfall at a station.

In this paper we borrow the Hashimoto et al. (1982) criteria developed for WRS to quantify rainfall characteristics in semi-arid Botswana.

The rainfall pattern impacts on the lives of Batswana in several ways. There have been severe floods and droughts in the past whereby a great deal of human suffering resulted. Rivers are subject to many random influences such as rainfall extremes, giving rise to floods or drought (Hall and Dracup, 1970). During the 1983/84 drought, it cost the Botswana Government US\$ M51 939 to mitigate the impacts of drought (CSO, 2000). Most of the Batswana still depend on agriculture (commercial and subsistence) for both food and income, hence rainfall deficiency affects crop and livestock production. During the 1985 drought, there was a reduction 


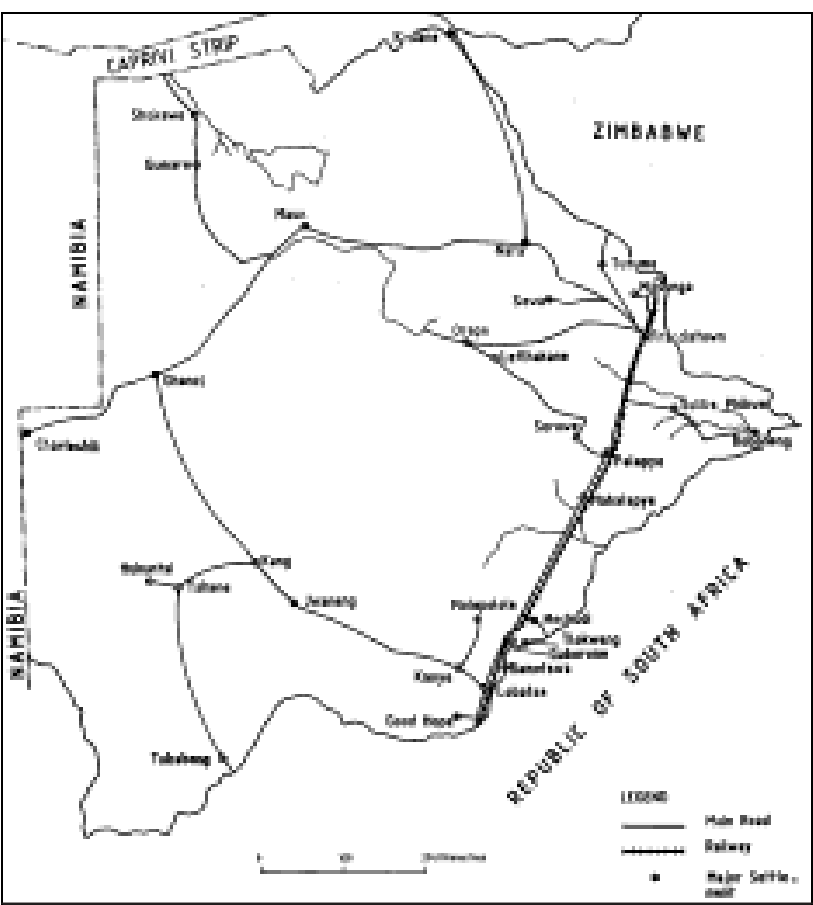

Figure 1

Locations of some rainfall stations used in this study

of $87 \%$ in crop production (CSO, 2000). Moreover, the cattle birth rate is positively correlated to rainfall (Clark and Quin, 1949; Frisch and Vercoe, 1977; Frisch and Vercoe, 1984; King, 1983). Both the surface water and groundwater resources depend on rainfall for recharge.

In Botswana, the known reliable record of floods starts in 1995. Areas severely affected were Palapye, Serowe, Mahalapye and Boteti (fatalities were recorded in these areas). In five veterinary districts, 128 farmers were affected. They lost 26 cattle, 1139 goats, 20 sheep, 90 donkeys and 3535 chickens (CSO, 2000). There has since been other flood in 2000 though the damage was less severe than during the 1995 floods.

The majority of towns and villages in Botswana use sewage ponds to treat sewage and landfills for solid waste. It is vital that areas vulnerable to severe floods be identified to enable designers to mitigate the impacts of floods on these waste facilities and protect against contamination of scarce water resources.

The objective of this study is to quantitatively characterise rainfall reliability and vulnerability in semi-arid Botswana.

\section{Methodology}

Rainfall data from 14 stations (cities, towns and major villages) spanning 26 years (1970 to 1995) were used to calculate reliability (Eq. 5) and vulnerability (Eq. 4) of rainfall in Botswana. Botswana is a totally land-locked country lying between latitudes $18^{\circ} \mathrm{S}$ and $27^{\circ} \mathrm{S}$ and longitudes $20^{\circ} \mathrm{E}$ and $29^{\circ} \mathrm{E}$ in Southern Africa. For simplicity it is assumed that rainfall depth is the major determinant of the flood peak in the calculation of flood vulnerability. Figure 1 shows the locations of rainfall stations used in this study.

To calculate reliability, let us define the following conditions:

$\mathrm{Z}_{\mathrm{t}}=1$ if annual rainfall $\mathrm{X}_{\mathrm{t}}$ for a particular station is greater than the long-term annual rainfall for that particular station $\left(X_{t} \in S\right)$ and $Z_{t}=0$ if annual rainfall $X_{t}$ for a particular station is less than the long-term annual rainfall for that particular station $\left(\begin{array}{ll}X_{t} & F\end{array}\right)$. where:

$\mathrm{Z}_{\mathrm{t}}$ value approximates cumulative distribution function of $\mathrm{X}_{\mathrm{t}}$.

Then:

Records from the rainfall stations network operated by the Department of Meteorological Services (DMS) and the Department of Water Affairs (DWA) in Botswana show that a few stations had been operating as early as 1939. Because of the missing data and coarse distribution of stations in the earlier years of data recording, only about 25 to 30 years of reliable data is available. Multiple nonlinear regression techniques were used to generate 72 years of rainfall data for different stations used in this study (NAMPAD, 2000; BNWMP, 1991). These data were generated by developing regression equations using available long-term rainfall data and then using these equations to fill in missing data. The accuracy of the results was measured by the coefficient of determination. The coefficient varied from 0.70 to 0.90 (BNWMP, 1991). Double mass curve technique was used to verify the consistency of the rainfall data prior to the above analysis. A dry year was defined as a year with rainfall less than or equal to 0.9 of the multi-annual average at a given station. A wet or rainy year was defined as one with rainfall to 1.2 of the multi-annual average at the station (NAMPAD, 2000).

Correlation coefficients were calculated for reliability and risk values obtained using the Hashimoto et al. (1982) method, which uses actual rainfall data and the NAMPAD (2000) method which uses the number of dry and wet years based on 72 years of actual and calculated rainfall data.

\section{Results and discussions}

The reliability values are based on the long-term annual rainfall for each station, so a 0.50 reliability value means that the rainfall for that particular station is half of the time equivalent to the long-term rainfall. If other benchmark values such as percentage of maximum attainable rainfall at a particular or the average for the whole country; probabilities of exceedance of annual rainfalls were used, then reliability values would be much lower than 0.5 because Botswana is arid. This approach is consistent with the definition of drought in Botswana (i.e. when annual rainfall is below long-term average then the Government normally declare the year as a drought year). Figure 2 shows the reliability values for rainfall to be above 0.5 in a given year, for most rainfall gauging stations. The risk graph shows the probability of having drought at each location. Risk is based on rainfall amount in a particular year being less than the long-term average rainfall for a particular station. Water supply for cities and major towns is from surface reservoirs or a network of reservoirs. Hence high risk does not necessarily mean "no water" though water conservation measures like water rationing could be imposed. The capital city Gaborone has a reliability of about 0.5 that is half the time the rainfall will be above or below long-term average. This is similar to Serowe, a town in the central region. Apart from Mahalapye, most places have rainfall reliability greater than 0.5 but less than 0.7. The implication here is that Mahalapye is prone to drought. hence risky for rain-fed agriculture. In the past, a lot of dry-land farming trials were carried out in this region (MoA, 1978). As expected the results were not good. Had this information been available, these trials may never have been carried out in the first place. Shakawe and Maun are located in the northern part of Botswana; here rainfall reliability is around 0.7.

Figure 3 is a plot of reliability calculated by using the two methods of Hashimoto et al., 1982 and number of wet/rainy year 
Figure 2

Rainfall reliability and risk using Hashimoto et al. method for selected stations in Botswana
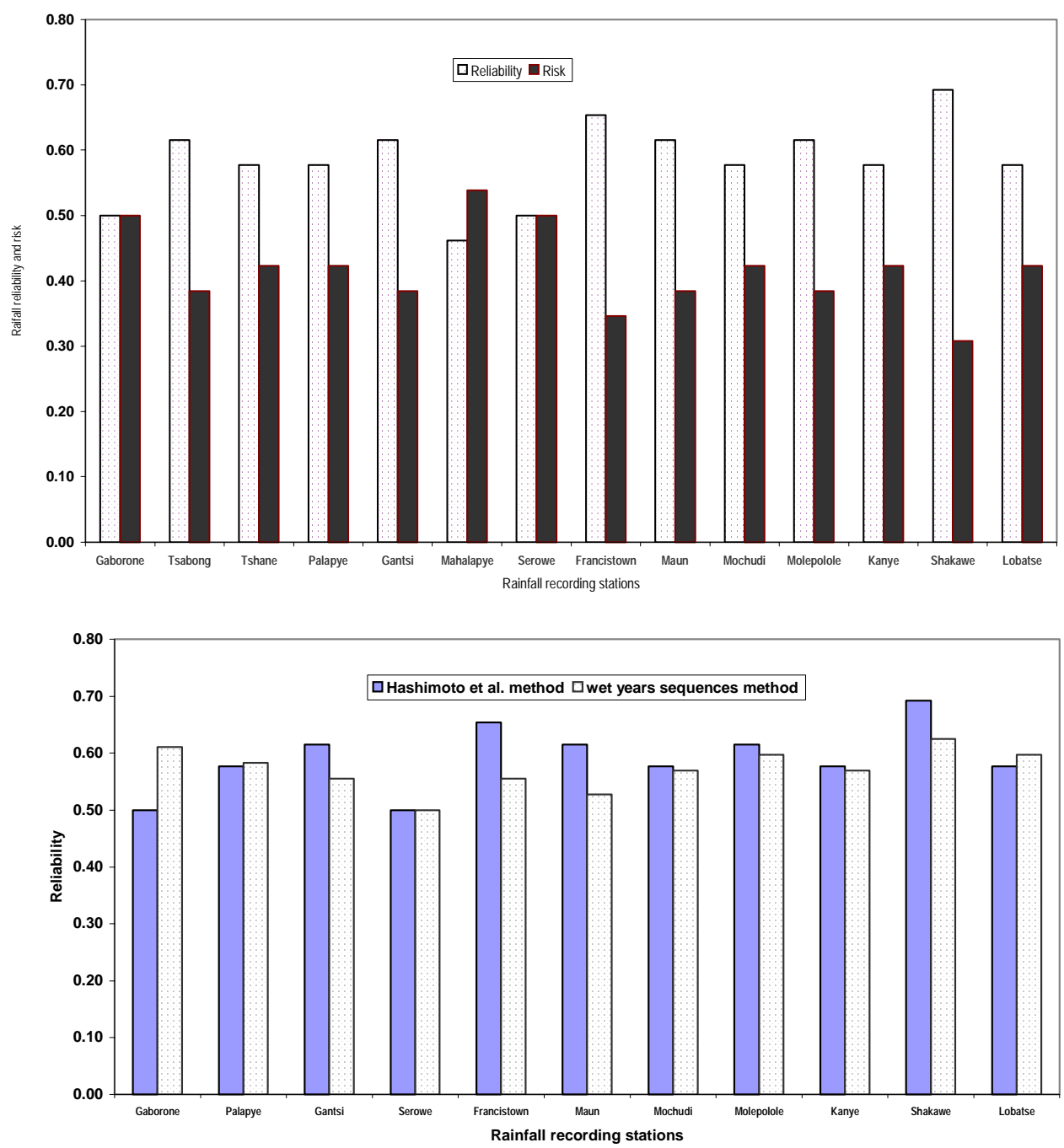

sequences (NAMPAD, 2000) for some stations. The correlation coefficient $0.28(\mathrm{P}<0.2)$, Fig. 3, shows significant differences in the two methods at Gaborone, Maun, Francistown and Gantsi stations. Removing these stations from the correlation coefficient calculation improves the correlation coefficient to $0.90(\mathrm{P}<0.005)$. An explanation of these differences is not obvious, but it might be due to the generated data for these four stations. For Gaborone, the wet year sequence method gives a higher reliability while the Hashimoto et al., 1982 method gives a higher reliability for the other three stations.

Figure 4 is a plot of risk and number of dry years for some stations. The correlation between the risk and number of dry years is $0.28(\mathrm{P}<0.2)$, though there are again significant differences at the four stations previously identified. Removing these stations from the equation improves the correlation coefficient to $0.90(\mathrm{P}<0.005)$. Statistics from data shown in Fig. 3 and Fig. 4 are similar because reliability is defined as one minus risk $(\alpha=1-r)$ and also (number of wet/rainy years $=72-$ number of dry years)

Figure 5 shows the vulnerability to drought (rainfall below long-term average for each station) and vulnerability to flooding (rainfall above long-term average for each station) at different stations in Botswana. Gaborone is the least vulnerable to drought (i.e. the maximum annual rainfall deficit of about $200 \mathrm{~mm}$ ever recorded). This result is interesting as Gaborone is the capital city and has the largest population. Water supply for the city of Gaborone comes from a series of surface water reservoirs, though for a long time it relied on the Gaborone dam and Molatedi dam in South Africa. The vulnerability to drought is more or less similar for all the places considered. The towns of Gantsi, Maun, Molepolole, Kanye and Lobatse are slightly more drought vulnerable than other places (i.e. maximum rainfall deficit, $\left(\left|X_{t}-X_{o}\right|>300 \mathrm{~mm}\right)$. It is therefore vital that their water supply be augmented i.e. be included in the water resource system which draws water from the reservoirs in the north of the country. For vulnerability to flooding, Palapye and Serowe were the highlight during the 1995 floods; $87 \%$ of casualties were in these areas (CSO, 2000). Although the town of Maun seems not vulnerable to flooding (the lowest in this study), international rivers could increase the potential to flooding. Mahalapye is also rated low in terms of vulnerability to flooding, but the two rivers passing through this town could significantly increase this vulnerability.

\section{Conclusions}

Apart from the town of Mahalapye, most places have rainfall reliability greater than 0.5 but less than 0.7 . The implication here is that Mahalapye is prone to drought hence too risky for rain-fed agriculture. Shakawe and Maun towns are located in the northern part of Botswana where rainfall reliability is around 0.7. These are areas where commercial dry-land farming or rain-fed agriculture could be practised. Most wildlife resides in these areas. It can also be pointed out that Pandamatenga (area declared for commercial 


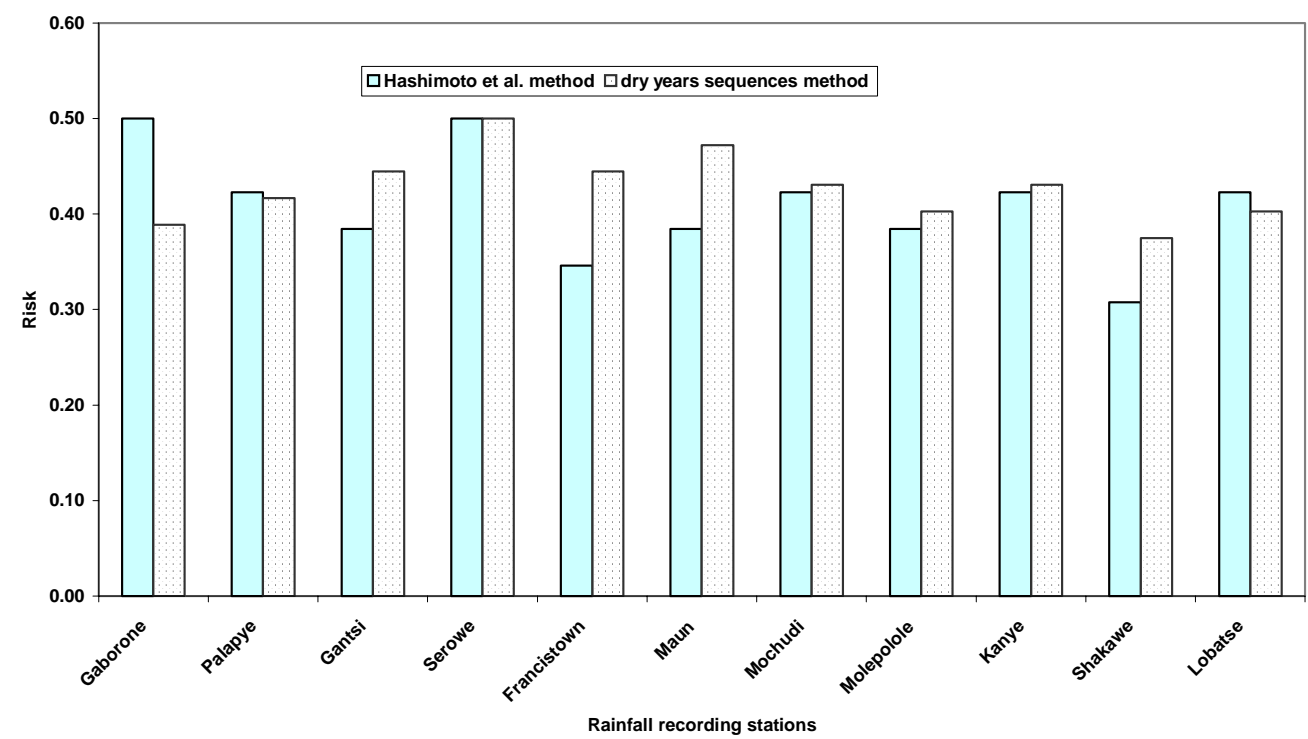

Figure 4

Rainfall risk values for selected stations using the two methods

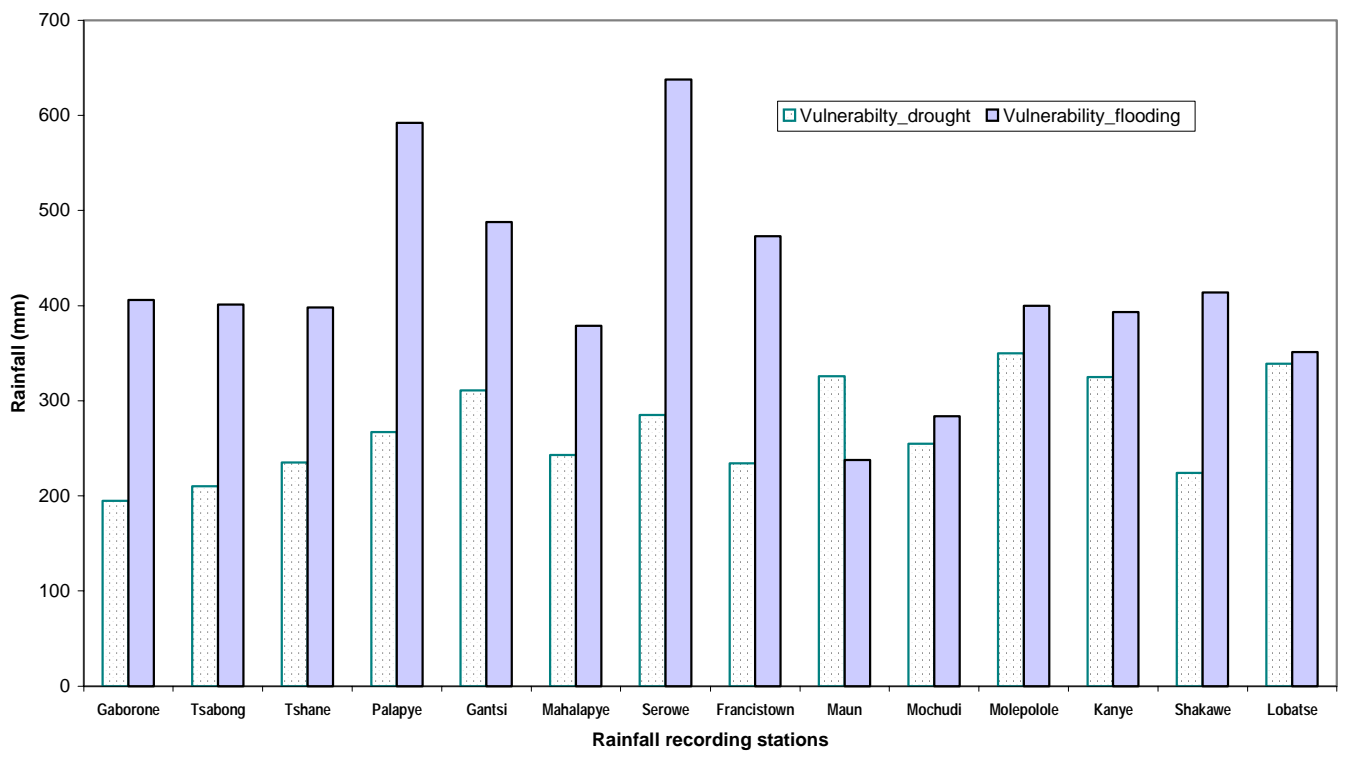

Figure 5

Drought and flooding vulnerability for selected stations in Botswana

farming), falls within this belt.

Vulnerability to drought is more or less similar for all the places considered. For vulnerability to flooding, Palapye and Serowe were the highest during the 1995 floods; $87 \%$ of casualties were in these areas. The highest ever rainfall of $1103 \mathrm{~mm}$ was recorded in Serowe in the 1987/88 season. The rainfall intensity data that could have enhanced this analysis are regrettably not available.

\section{References}

BNWMP (1991) Final Report, Volume 6-Hydrology. SMEC, WLPU and SGAB. Gaborone, Botswana.

CLARK R and QUIN JL (1949) Studies on the water requirements of farm animals in South Africa. 1. Effects of intermittent watering on Merino sheep. Onderstepoort J. Vet. Sci. 22 335-356.

CSO (2000) Botswana Environmental Statistics, Department of Printing and Publishing Services, Gaborone, Botswana.

FRISCH JE and VERCOE JE (1977) Food intake, eating rate, weight gains, metabolic rates and efficiency of feed utilization in Bos taurus and Bos indicus crossbred cattle. Anim. Prod. 25 353-358.
FRISCH JE and VERCOE JE (1984) Analysis of growth of different cattle genotypes reared in different environments. J. Agric. Sci. Camb. 103 137-153.

HALL WA and DRACUP JA (1970) Water Resources Systems Engineering. McGraw-Hill, New York.

HASHIMOTO T, STEDINGER JR and LOUCKS DP (1982) Reliability, resiliency, and vulnerability criteria for water resource system performance and evaluation. Water Resour. Res. 18 (1) 14-20.

KING JM (1983) Livestock water needs in pastoral Africa. Res. Rep. No.7. International Live-stock Center for Africa (ILCA), Addis Ababa.

LINSLY RK, KOHLER MA and PAULHUS JLH (1982) Hydrology for Engineers. McGraw-Hill, New York.

LOUCKS DP, STEDINGER JR and HAITH DA (1981) Water Resources Systems Planning and Analysis. Prentice-Hall, New Jersey.

MoA (1978) Annual Report For The Division of Crop Research. Department of Agric. Res., Gaborone, Botswana.

NAMPAD (2000) Final Report, Volume 4. Climate, Soils and Water. TAHAL Consulting Engineers.

WINDSOR JS (1973) Optimization model for the operation of flood control systems. Water Resour. Res. 9 (5) 1219-1226. 